\title{
The comparative analysis of performance indicators and information disclosure for BIDs and area-based management in the US, UK, and Japan
}

\author{
J. Mitarai ${ }^{1} \&$ N. Suebsuk ${ }^{2}$ \\ ${ }^{I}$ Graduate School of Management, Kyoto University, Japan \\ ${ }^{2}$ Faculty of Architecture, Kyoto Institute of Technology, Japan
}

\begin{abstract}
Business improvement districts (BIDs) and area-based management (ABM) represent independent actions taken by a group of property owners or business operators in cooperation with local government for improving the business environment and value of the area concerned. In the US and UK, BIDs are managed by special assessments, levies, or taxes on property owners or business operators. In Japan, there are no BIDs but there are some private organisations called ABMs which manage the area by cognate fields, such as enhancing the clever use of existing infrastructure, social capital, safety and sanitation, beautiful landscape, and business promotion, with strategic thinking on management and sustainability. This research provides a comparative study on research performance indicators and information disclosed by BID and ABM organisations, focusing on the cities of New York, London, and Tokyo. It uses a survey of 227 indicators and numerical information from the annual reports of two organisations in each city and compares them through the view point of the amount, outputoutcome, and nine original categories. In conclusion, the difference relates to the characteristics and purpose of the system in each city. For New York, they emphasise clean and green and announce their activities in accordance with the sunset provision. In London, marketing and economics is emphasised, according to the organisational objectives, and use outcome data as a performance indicator. Whereas, in Tokyo, disclosed data is less and varies by area since there is no BID system. From the analysis, this study suggests certain ideas on information and indicators for introducing a BID system to current non-BID using countries.
\end{abstract}


Keywords: business improvement districts, Area-based management, performance indicator, evaluation, public-private partnership, output-outcome.

\section{Introduction}

Recently, in Japan has tended to face a population decrease followed by low growth rates and financial stringency. Difficulties with maintenance and improvement are likely to become the main problems for the country. Besides city development, management is now playing a more important role through cooperation between public and private sectors. For this reason, Area-based Management (ABM) is now becoming common in Japan. However, the performance of $\mathrm{ABM}$ need to be evaluated in order to support fundraising for stakeholders or organisation members. Unfortunately, there is little data on the evaluation of ABMs in Japan. In contrast, there is a great deal of performance data and activity information on Business Improvement Districts (BIDs) available to the public in the US and UK. The US, UK and Japan are some of the largest economic powers in the world. In addition, the US has pioneered BIDs since the beginning, the UK has recently successfully raised many BIDs since 2005, and Japan, although currently without a BID system, is considering its introduction and is, therefore, the priority concern of this research.

\section{Background of the study}

\subsection{BIDs in the US and UK}

BIDs are partnerships between local authorities and local businesses which are intended to provide additional services or improvements to a specified area [1]. BIDs are funded in whole or part by special assessments, levies, or additional taxes on business operators in the UK and property owners in the US.

More than 30 years ago in the US, BIDs were created to solve the problem of a deteriorating fiscal situation in the city government with the degeneration of the maintenance of public spaces. It initiated from a petition by property owners in the defined area whereby businesses pay special assessments or levies in order to manage project funding within the district's boundaries. The US BIDs work to provide services such as street cleaning, security, capital improvement, pedestrian and streetscape enhancement, and marketing the area. In the UK, BIDs are still in the early stage. Even the earliest approved BIDs in the UK have only been operating since early 2005. BIDs in England are developed in the context of a functional local government system and the range of other economic and social development initiatives, impacting on the scale and scope of BID activities [4]. Most UK BIDs are governed by a board made up of levy payers representing the area concerned. UK BIDs are about increased footfall, business cost reduction, area promotion, facilitated networking opportunities with neighbouring businesses, and assistance in dealing with the council/police and other public bodies. The BID establishment process started with petitions by property owners, tax payers or other people in the area. BIDs must be agreed by a voting process (ballot in the 
England or $2 / 3$ support by property owners and not more than $51 \%$ of deny signatures in New York). Within the legislative framework and following approval by local government, BIDs operate for a maximum of approximately five years. If they wish to continue they must go through a voting and approval process for terms of up to approximately five more years. This system is called the sunset provision. Therefore, it is important for BIDs to measure performance by demonstrating the return on investment in order to special assessments, levies, or additional taxes payers through activities in the area.

\subsection{ABMs in Japan}

In Japan, there is no BID system because no national BID law completely different to that of the US and UK. However, Osaka has just established an "Osaka style BID" system, and it is the first and only BID organisation in existence in the country. In contrast to the US and UK, the Osaka BID system uses the charge or levy structure under the scope of local government projects by the general law of local administration, namely the Local Autonomy Act. According to the Act, the charge or levy payer is not involved and plays no part in any decisions on the establishment of the BID organisation, and the charge is not paid to the BID organisation automatically. It can therefore be said that the BID system in Osaka is still inadequate. At present, the local city government in Osaka is asking the Japanese National Government to introduce laws on the BID system and discussions on their introduction are still continuing.

However, in Japan there is a system called ABM which concerns partnerships between local authorities and businesses or residents' group which are intended to provide additional services or improvements to a specified area. In 2005, the Ministry of Land, Infrastructure, Transport and Tourism (MLIT) distributed a manual of ABMs to promote them. Nowadays, there are lots of ABMs in Japan. Research which indicates that there are at least 574 ABM organisations [2]. ABMs use cognate fields, such as enhancing the clever use of existing infrastructure, social capital, safety and sanitation, beautiful landscape, and business promotion, with strategic thinking on management and sustainability. The only BID organisation in Japan is Grand Front Osaka TMO. However, their annual report is not disclosed to the public. Therefore, the annual report of an ABMs is used for comparison in this research.

\subsection{Literature review}

Performance indicators and numeric information from the US and UK have been found in certain documents; one from the Department of Small Business Services in NewYork (SBS) [3] and others in the UK from the Department of Communities and Local Government [4] and British BID academy 2015 [5]. For US, the [3] a report on the comparative data of 72 BIDs in New York contains standard information intended to illustrate basic comparisons between individual and groups of BIDs in New York. In the UK, the [4] report is collected by an electronic and telephone survey of 750 businesses in 26 areas where BIDs are operating. A small amount of data concerning performance indicators and numeric information 
was found in small amounts (18 BID areas combining both large and small cities) in the UK. From the literature, there is little evidence concerning KPIs (only one chart with unsupported evidence) which is out of date (2007). The report [5] has aims to equip BID professionals with practical guidance and an understanding of performance management. The report has collected KPI groupings by tangible and intangible information without raw data of numeric indicators. In addition, for Japan, no collective report or previous study on ABM performance indicators and numeric information is available [13]. There are found only two ABMs among famous business area in Tokyo which publicly disclose information, whereas US and UK's BID information is widely available. Therefore, the originality of this paper concerns an up-to-date and comparative study of all the information disclosed in the annual reports from three large global business cities. Moreover, to collect information on the same scale, a comparative study of numerical information, and performance indicators from each annual report, two BIDs in New York, two in London, and two ABMs in Tokyo were used. The research priority is defined by implementing comparison analysis through the numerical viewpoint in nine categories and from the output-outcome aspect.

\section{Methodology and purpose of the study}

In this study, all numerical information, except that involving revenue and expenses was obtained from up-to-date annual reports of some BIDs in the US and UK and certain ABMs in Japan. The reason for selecting all the numerical information is that "distinguishing between town centre and BID performance is very difficult" [6]. As a result, 227 performance indicators and numerical information from six annual reports were collected and termed jointly as "indicators". The chosen BIDs and ABM are Grand Central Partnership (GCP) and Downtown Alliance (DTA) in New York, Victoria (VTR) and Leicester Square to Piccadilly Circus BID (LCQ to PDC) in London, and Otemachi/ Yurakucho/Marunouchi (OYM) and Kabukicho (KBK) in Tokyo. Reasons for the selection of the BIDs in New York and London are: location, business and commercial prominence, large budget, and amount of performance indicators and numerical information disclosed in the annual report. For Tokyo, only the two previously mentioned ABMs among eight situated in the prominent business area disclose performance indicators and numerical information in the annual report. The purpose of the study is to compare the situation about the evaluation of BID performance and information disclosure. The "indicators" are analysed as follows:

- $\quad$ By counting the total number of indicators and summarising each of the 227 indicators.

- By carrying out a comparative analysis of the 227 indicators, grouping the effect of BIDs and ABMs in nine categories (Table 1).

- By analysing the performance of 227 indicators, following the original outputoutcome (Table 2).

- The indicators of each will be counted with the percentage by the total indicators' number of each cities in nine categories (Table 4) and of each BID or ABM in output-outcome (Table 5) to compare overall image. 
From the analysis, certain ideas are suggested as to the disclosure of performance indicators and numerical information in the wider context of specific issues, to introduce the BID approach to non-BID countries for sustainability of cities in the future.

Table 1: Nine categories.

\begin{tabular}{|c|c|c|}
\hline Main Categories & Sub Categories & Number \\
\hline \multirow{3}{*}{ (1) Indicators of Machinami or scenery } & Sanitation and cleanliness & $1-\mathrm{a}$ \\
\hline & Streetscape, Beautification and Greenery & $1-b$ \\
\hline & Others (volunteers /BIDs design identity) & $1-\mathrm{c}$ \\
\hline \multirow{5}{*}{$\begin{array}{l}\text { (2) Indicators of visitors (clients, } \\
\text { customers, passengers, travellers, tourists, } \\
\text { etc.) }\end{array}$} & $\begin{array}{l}\text { Marketting communication and special events/ holiday } \\
\text { lighting highlights and decoration }\end{array}$ & $2-a$ \\
\hline & Transportation (ferry, bus, train rider/ route,bicycle or taxi ) & $2-b$ \\
\hline & Visitor service (multi-language guide, etc.) & $2-\mathrm{c}$ \\
\hline & Visitors numbers \& hotels visitors & $2-d$ \\
\hline & Others & $2-f$ \\
\hline \multirow{7}{*}{$\begin{array}{l}\text { (3) Indicators of real estate (rental costs, } \\
\text { vacancy rates, etc.) }\end{array}$} & General/ Total & $3-\mathrm{a}$ \\
\hline & Restaurant \&bar/retails & $3-b$ \\
\hline & Hotel room number / Percentage of luxury class & $3-\mathrm{c}$ \\
\hline & Office/Commercial office space & $3-d$ \\
\hline & Residential & $3-e$ \\
\hline & Special purpose: gym, sport, etc. & 3-f \\
\hline & Others & $3-\mathrm{g}$ \\
\hline \multirow{6}{*}{$\begin{array}{l}\text { (4) Economic indicators (consumption } \\
\text { activity or merchandise, employment, etc.) }\end{array}$} & Employment & $4-\mathrm{a}$ \\
\hline & Business & $4-b$ \\
\hline & Investments & 4-c \\
\hline & Activity & 4-d \\
\hline & Revenue (grants, funds, tax, additional etc) & 4-e \\
\hline & Others & 4-f \\
\hline \multirow{3}{*}{$\begin{array}{l}\text { 5) Indicators for disaster prevention, } \\
\text { crime prevention, or public safety }\end{array}$} & Public safety and security & $5-a$ \\
\hline & Disaster & $5-b$ \\
\hline & Other (number of homeless) & $5-\mathrm{c}$ \\
\hline \multirow{4}{*}{$\begin{array}{l}\text { (6) Indicators for enhancing community } \\
\text { power, mutual understanding, or networking }\end{array}$} & Social media number involve on BID marketing program & $6-a$ \\
\hline & WiFi program & $6-b$ \\
\hline & Surveys of public need / Annual meeting & $6-c$ \\
\hline & Others & $6-d$ \\
\hline \multirow{5}{*}{$\begin{array}{l}\text { (7) Indicators for enhancing the popularity } \\
\text { of the BID, ABM or their areas }\end{array}$} & Award/ Prize & $7-\mathrm{a}$ \\
\hline & Vote & $7-b$ \\
\hline & Newsletter or digital letter subscriber & $7-\mathrm{c}$ \\
\hline & \begin{tabular}{|l} 
Published press, TV or news papers, etc. \\
\end{tabular} & $7-\mathrm{d}$ \\
\hline & Others & 7-e \\
\hline \multirow{2}{*}{$\begin{array}{l}\text { (8) Indicators of the competition between } \\
\text { regions (increase in employees, population growth) }\end{array}$} & Population growth & $8-a$ \\
\hline & Others & $8-b$ \\
\hline \multirow{6}{*}{ (9) Others } & General and Administrative functions & $9-\mathrm{a}$ \\
\hline & Approval of quality of life / rating & $9-b$ \\
\hline & Market segmentatin & $9-\mathrm{c}$ \\
\hline & Others & $9-d$ \\
\hline & Ecology & 9-e \\
\hline & Social welfare (charity) & 9-f \\
\hline
\end{tabular}


Table 2: Output outcome.

\begin{tabular}{|c|c|l|}
\hline 1 & input & $\begin{array}{l}\text { The amount of input resources such as budget and personnel } \\
\text { for works or activities. }\end{array}$ \\
\hline 2 & output & $\begin{array}{l}\text { The amount of production by works or activities (goods and } \\
\text { services); maintenance of infrastructure, number of times } \\
\text { events have been held. }\end{array}$ \\
\hline outcome & $\begin{array}{l}\text { The value (result) created by works or activities attributed to } \\
\text { target groups. The usage and quality of such works or } \\
\text { activities (including hardware and software) and their effect } \\
\text { on people and society. Influence brought directly to the target } \\
\text { work and activities groups. Short to medium term effect; } \\
\text { number of participants in events, number of users or attendees } \\
\text { at events organised by the BID, and satisfaction of those } \\
\text { events or facilities managed by them. }\end{array}$ \\
\hline impact & $\begin{array}{l}\text { The indirect effect generated by utilising the result of their } \\
\text { work or activities on the economy, society (ripple effect), and } \\
\text { the non-target group. It is often not recognised that such effect } \\
\text { can be caused by BID works or activities, whether or not } \\
\text { intentional. Indicators of both outcome and impact are } \\
\text { categorised as impact. }\end{array}$ \\
\hline
\end{tabular}

\section{Case study: performance indicators and information disclosure}

\subsection{New York BIDs (NYC BIDs)}

\subsubsection{Grand Central Partnership (GCP)}

GCP was established in 1988, the oldest in NY and one of the largest BIDs in the US. GCP serves approximately 7,100,000 $\mathrm{m}^{2}$ of Midtown Manhattan surrounding Grand Central Terminal, a landmark transportation hub. As a NPO, GCP is frequently cited worldwide as a model of how city centres can undergo a remarkable recovery. From the annual report [7] FY2012/2013, revenue is shown as 13,454,971 USD (assessment 94.4\%). The expenses for the programme can be divided by: public safety $19 \%$, sanitation $24.8 \%$, external affairs $6 \%$, capital improvements $17.6 \%$, district-wide maintenance $8.9 \%$, horticulture $3.2 \%$, and social services $1.1 \%$. Interesting indicators of GCP are the amount of garbage collected and street furniture distribution; sign poles, ornamental trees, bicycle racks, etc.

\subsubsection{The Alliance for Downtown New York (DTA)}

DTA was established in 1995 and has been working to enhance the quality of life in the Lower Manhattan (LM) area; DTA serves more than approx. $360,000 \mathrm{~m}^{2}$ in LM, the main business and economic area on the waterfront of NY and New World Trade Centre. The annual report [8] FY2013/2014 shows revenue 18,945,738 USD (assessment revenue 85.6\%). The expenses for the programme can be 
divided by: public safety $19.5 \%$, sanitation $26.2 \%$, communications $16.9 \%$, economic development $12.3 \%$, transportation $10.7 \%$, and social services $2.3 \%$. Interesting indicators of DTA are the amount of additional open spaces or outdoor mobile kiosks, alliance bus services or ferries, homeless numbers, public safety crew, etc.

\subsection{London BIDs (LD BIDs)}

\subsubsection{Victoria Business Improvement District (VTR)}

VTR was established in April 2010 as a not-for-profit company limited by guarantee. The VTR BID was originally formed with approx. 480,000 $\mathrm{m}^{2}$ of business. The VTR is administered by the City of Westminster where there is a mix of iconic historic attractions, state-of-the-art commercial and residential architecture, plus world-class hotels and a wide range of restaurants and bars. From annual report [9] FY2015, revenue was 1,983,345 GBP (levy 90.4\%). The expenses for the programme can be divided by: safe and secure $9.5 \%$, clean and green $20.8 \%$, the Showcase Victoria marketing programme $9.3 \%$, other marketing programmes such as Prosperous Economy 13.8\%. Interesting indicators of VTR mostly concern events, safety seminars, cameras provided for local police teams, business-based volunteers or Metropolitan Police volunteers, security hours delivered by private companies, crime prevention items, etc., as well as those of social media.

\subsubsection{Leicester Square to Piccadilly Circus (LCQ to PDC)}

LCQ to PDC BID area was established in 2005, one of two operated under the Heart of London Business Alliance, and the first central LD BID. LCQ to PDC serves 32 streets and more than 500 businesses including located arts and galleries, theatres, and many luxury shops. Its purpose is to support the commercial wellbeing of businesses and organisations, representing and promoting the district to a global audience as a prominent global cultural, entertainment, shopping and dining destination in LD's West End. From annual report [10] FY2012/2013 revenue was shown at 1,004,000 GBP (levy 89.2\%). The expenses for the programme can divided by: events such as Connecting with You 6.9\%, integrated street management $38.9 \%$, marketing $4.5 \%$, and positioning and promotion $16.3 \%$. Interesting indicators are reported on real estate rental costs, crime prevention, floor space usage, international brands in the area, memberships joining safety programmes such as the radio link scheme.

\subsection{Tokyo ABMs (TK ABMs)}

\subsubsection{Otemachi/Yurakucho/Marunouchi (OYM)}

The area of OYM, Dai-Maru-Yu in Japanese, is about $1,200,000 \mathrm{~m}^{2}$ in a large city core area of TK, and a prominent world-class business area. There are also some ABM organisations in the area, one of which is the council for Area Development and Management, founded in 1988. The council's members are property owners in the OYM district who work together to carry out initiatives to ensure the sustainable development of the area. Another is the Association for Creating 
Sustainability in Urban Development founded in 2007. The Association works closely with companies in the OYM district and their employees, putting together $\mathrm{R} \& \mathrm{D}$ and business plans which explore next-generation work styles. In all of these activities, the goal is to help resolve environmental, health, and other social issues. Another is the OYM Area Management Association founded in 1988. The association works for the enhancement of the OYM district's brand by utilising roads and other public spaces and holding disaster prevention and environmental activities. Their revenues and expenses is not disclosed [11]. Interesting indicators are report on pedestrian traffic or bus passenger, number of railway line and shuttle bus, floor space area, number of building, etc.

\subsubsection{Kabukicho (KBK)}

$\mathrm{KBK}$ is one of the most famous entertainment districts, with a lot of theatres, restaurants, pubs, and nightspots located near Shinjuku station in TK. KBK Town Management is a non-juridical private organisation founded in 2008 with the aim of accomplishing district safety and entertainment. The organisational activities: firstly, transmitting information concerning shops and events through the website. Secondly, the organisation provides safe and secure activities; cleaning and patrol. Thirdly, revitalisation of the area, creating and transmitting new culture and visitor prosperity by organising events in parks or plazas. Lastly, to implement, discuss, and publish future guidelines for KBK, formulated together with local government. The information of their working area, revenue, and expenses is not disclosed in the annual report [12]. Interesting indicators are the number of visitors at the event, safety patrol days, number of website visits, Facebook page postings, etc.

\section{Comparison}

\subsection{Indicator analysis by category}

From the annual report, indicators were selected and grouped by nine categories as mentioned in the methodology (Table 1). The data is shown in Table 3.

Table 3: Six annual report indicators divided into nine categories.

\begin{tabular}{|c|c|c|c|c|c|c|c|c|c|c|c|c|c|c|c|c|c|c|c|c|c|}
\hline \multirow{2}{*}{ BID } & \multicolumn{3}{|c|}{ (1) } & \multicolumn{5}{|c|}{ (2) } & \multicolumn{7}{|c|}{ (3) } & \multicolumn{6}{|c|}{ (4) } \\
\hline & 1-a & 1-b & $1-\mathrm{c}$ & 2-a & $2-b$ & $2-\mathrm{c}$ & $2-d$ & $2-\mathrm{f}$ & 3-a & 3-b & $3-\mathrm{c}$ & $3-\mathrm{d}$ & $3-e$ & 3-f & $3-\mathrm{g}$ & $4-\mathrm{a}$ & 4-b & $4-\mathrm{c}$ & $4-d$ & $4-\mathrm{e}$ & $4-\mathrm{f}$ \\
\hline GCP & 4 & 11 & 0 & 0 & 3 & 1 & 3 & 0 & 0 & 3 & 1 & 1 & 0 & 0 & 0 & 0 & 0 & 0 & 0 & 0 & 0 \\
\hline \begin{tabular}{|l|} 
DTA \\
\end{tabular} & 6 & 9 & 0 & 1 & 8 & 1 & 1 & 0 & 1 & 0 & 3 & 2 & 1 & 0 & 0 & 3 & 2 & 1 & 0 & 0 & 0 \\
\hline VTR & 3 & 6 & 4 & 7 & 1 & 5 & 0 & 0 & 0 & 0 & 0 & 0 & 0 & 0 & 0 & 0 & 1 & 1 & 5 & 0 & 0 \\
\hline LSQtoPDC & 3 & 3 & 0 & 5 & 0 & 0 & 1 & 0 & 2 & 3 & 1 & 0 & 0 & 2 & 0 & 1 & 3 & 0 & 0 & 0 & 0 \\
\hline \begin{tabular}{|l|} 
OYM \\
\end{tabular} & 0 & 2 & 0 & 0 & 3 & 0 & 3 & 0 & 4 & 0 & 0 & 0 & 0 & 0 & 0 & 1 & 0 & 0 & 0 & 0 & 0 \\
\hline \begin{tabular}{|l|} 
KBK \\
\end{tabular} & 0 & 0 & 0 & 2 & 0 & 0 & 0 & 0 & 0 & 0 & 0 & 0 & 0 & 0 & 0 & 0 & 1 & 0 & 0 & 0 & 0 \\
\hline \begin{tabular}{|l|} 
Total \\
\end{tabular} & 16 & 31 & 4 & 15 & 15 & 7 & 8 & 0 & 7 & 6 & 5 & 3 & 1 & 2 & 0 & 5 & 7 & 2 & 5 & 0 & 0 \\
\hline \multirow{2}{*}{ BID } & \multicolumn{3}{|c|}{ (5) } & \multicolumn{4}{|c|}{ (6) } & \multicolumn{5}{|c|}{ (7) } & \multicolumn{2}{|c|}{ (8) } & \multicolumn{6}{|c|}{ (9) } & \multirow{2}{*}{ Total } \\
\hline & $5-\mathrm{a}$ & 5 -b & $5-\mathrm{c}$ & 6-a & 6-b & 6-c & 6-d & $7-\mathrm{a}$ & $7-b$ & $7-\mathrm{c}$ & $7-d$ & $7-\mathrm{e}$ & $8-\mathrm{a}$ & $8-b$ & $9-\mathrm{a}$ & 9-b & 9-c & $9-\mathrm{d}$ & $9-\mathrm{e}$ & 9-f & \\
\hline \begin{tabular}{|l|}
$\mathrm{GCP}$ \\
\end{tabular} & 1 & 0 & 0 & 0 & 0 & 0 & 0 & 0 & 0 & 0 & 0 & 0 & 0 & 0 & 0 & 0 & 0 & 0 & 2 & 0 & 30 \\
\hline DTA & 3 & 0 & 1 & 0 & 1 & 0 & 0 & 0 & 0 & 0 & 0 & 0 & 1 & 1 & 0 & 3 & 0 & 0 & 0 & 0 & 49 \\
\hline VTR & 18 & 1 & 0 & 1 & 0 & 0 & 0 & 1 & 1 & 9 & 1 & 5 & 0 & 0 & 0 & 0 & 0 & 0 & 0 & 2 & 72 \\
\hline LSQtoPDC & 4 & 0 & 0 & 0 & 0 & 0 & 0 & 0 & 0 & 6 & 3 & 3 & 0 & 0 & 0 & 0 & 0 & 0 & 3 & 0 & 43 \\
\hline \begin{tabular}{|l|} 
OYM \\
\end{tabular} & 0 & 1 & 0 & 0 & 0 & 0 & 1 & 0 & 0 & 0 & 0 & 0 & 0 & 0 & 0 & 0 & 0 & 0 & 2 & 0 & 17 \\
\hline KBK & 2 & 1 & 0 & 0 & 0 & 0 & 0 & 0 & 0 & 10 & 0 & 0 & 0 & 0 & 1 & 0 & 0 & 0 & 0 & 0 & 17 \\
\hline Total & 28 & 3 & 1 & 1 & 1 & 0 & 1 & 1 & 1 & 25 & 4 & 8 & 1 & 1 & 1 & 3 & 0 & 0 & 7 & 2 & 228 \\
\hline
\end{tabular}


In Table 3, 227 indicators have been collected, 30 for the GCP, 48 for DTA*, 72 for VTR, 43 for LSQ to PDC, 17 for OYM, and 17 for KBK. The highest indicators are those for (1) Machinami or scenery; 1-b streetscape, beautification, and greenery (31), followed by (5) disaster prevention, crime prevention, and public safety; 5-a safety and security (28) and those (7) to enhance the popularity of area management, and the profile of the Region; 7-c newsletters subscribers, digital letters (25).

Table 4 is the total indicators in NYC, LD and TK divided in nine categories details are shown below.

Table 4: Indicators and percentage of three cities divided into nine categories.

\begin{tabular}{|c|c|c|c|c|c|c|c|c|c|c|c|c|c|c|c|c|c|c|c|c|c|}
\hline \multirow{2}{*}{ BID } & \multicolumn{3}{|c|}{ (1) } & \multicolumn{5}{|c|}{ (2) } & \multicolumn{7}{|c|}{ (3) } & \multicolumn{6}{|c|}{ (4) } \\
\hline & $1-\mathrm{a}$ & 1-b & $1-\mathrm{c}$ & $2-a$ & $2-b$ & $2-c$ & $2-d$ & $2-\mathrm{f}$ & $3-a$ & $3-b$ & $3-\mathrm{c}$ & $3-d$ & $3-\mathrm{e}$ & $3-\mathrm{f}$ & $3-\mathrm{g}$ & $4-a$ & 4-b & $4-\mathrm{c}$ & $4-d$ & $4-\mathrm{e}$ & $4-\mathrm{f}$ \\
\hline US/NYC & 10 & 20 & 0 & 1 & 11 & 2 & 4 & 0 & 1 & 3 & 4 & 3 & 1 & 0 & 0 & 3 & 2 & 1 & 0 & 0 & 0 \\
\hline \begin{tabular}{|l|}
$\%$ \\
\end{tabular} & $12.7 \%$ & $25.3 \%$ & $\begin{array}{ll}\% & 0.0 \% \\
\end{array}$ & $1.3 \%$ & $13.9^{\circ}$ & \begin{tabular}{l|l|}
$\%$ & $2.5 \%$ \\
\end{tabular} & $5.1 \%$ & $0.0 \%$ & \begin{tabular}{|l|}
$1.3 \%$ \\
\end{tabular} & \begin{tabular}{|l|l|}
$3.8 \%$ & 5 \\
\end{tabular} & $5.1 \%$ & $3.8 \%$ & $1.3 \%$ & $0.0 \%$ & $0.0 \%$ & \begin{tabular}{|l|l|}
$3.8 \%$ & 2 \\
\end{tabular} & \begin{tabular}{|l|l|}
$2.5 \%$ & 1 \\
\end{tabular} & $1.3 \%$ & $0.0 \%$ & $0.0 \%$ & $0.0^{\circ}$ \\
\hline UK/LD & 6 & 9 & 4 & 12 & 1 & 5 & 1 & 0 & 2 & 3 & 1 & 0 & 0 & 2 & 0 & 1 & 4 & 1 & 5 & 0 & 0 \\
\hline$\%$ & $5.2 \%$ & $7.8 \%$ & \begin{tabular}{l|l}
6 & $3.5 \%$ \\
\end{tabular} & $10.4 \%$ & \begin{tabular}{l|l} 
& $0.9 \%$ \\
\end{tabular} & \begin{tabular}{l|l|}
$\%$ & $4.3 \%$ \\
\end{tabular} & $0.9 \%$ & $0.0 \%$ & $1.7 \%$ & \begin{tabular}{|l|l|l|}
$2.6 \%$ & 0 \\
\end{tabular} & $0.9 \%$ & $0.0 \%$ & $0.0 \%$ & $1.7 \%$ & $0.0 \%$ & \begin{tabular}{|l|l}
$0.9 \%$ & 3 \\
\end{tabular} & \begin{tabular}{|l|l|}
$3.5 \%$ & 0 \\
\end{tabular} & $0.9 \%$ & $4.3 \%$ & $0.0 \%$ & $0.0^{\circ}$ \\
\hline \begin{tabular}{|l}
$\mathrm{JP} / \mathrm{TK}$ \\
\end{tabular} & 0 & 2 & 0 & 2 & 3 & 0 & 3 & 0 & 4 & 0 & 0 & 0 & 0 & 0 & 0 & 1 & 1 & 0 & 0 & 0 & 0 \\
\hline$\%$ & $0.0 \%$ & $5.9 \%$ & \begin{tabular}{l|l|}
0 & $0.0 \%$ \\
\end{tabular} & $5.9 \%$ & $8.8 \%$ & \begin{tabular}{l|l|}
$\%$ & $0.0 \%$ \\
\end{tabular} & $8.8 \%$ & $0.0 \%$ & $11.8 \%$ & \begin{tabular}{|l|l|l|}
$0.0 \%$ & 0 \\
\end{tabular} & $0.0 \%$ & $0.0 \%$ & $0.0 \%$ & $0.0 \%$ & $0.0 \%$ & \begin{tabular}{|l|l|}
$2.9 \%$ & 2 \\
\end{tabular} & \begin{tabular}{|l|l|}
$2.9 \%$ & $\mathrm{C}$ \\
\end{tabular} & $0.0 \%$ & $0.0 \%$ & $0.0 \%$ & $0.0 \%$ \\
\hline \multirow{2}{*}{ BID } & \multicolumn{3}{|c|}{ (5) } & \multicolumn{4}{|c|}{ (6) } & \multicolumn{5}{|c|}{ (7) } & \multicolumn{2}{|c|}{ (8) } & \multicolumn{6}{|c|}{ (9) } & \multirow{2}{*}{ Total } \\
\hline & $5-a$ & 5-b & $5-\mathrm{c}$ & 6-a & 6-b & 6-c & $6-d$ & $7-a$ & $7-b$ & $7-c$ & $7-d$ & $7-\mathrm{e}$ & $8-a$ & 8-b & $9-\mathrm{a}$ & $9-\mathrm{b}$ & $9-\mathrm{c}$ & $9-\mathrm{d}$ & $9-\mathrm{e}$ & $9-\mathrm{f}$ & \\
\hline US/NYC & 4 & 0 & 1 & 0 & 1 & 0 & 0 & 0 & 0 & 0 & 0 & 0 & 1 & 1 & 0 & 3 & 0 & 0 & 2 & 0 & 79 \\
\hline$\%$ & \begin{tabular}{|l|}
$5.1 \%$ \\
\end{tabular} & $0.0 \%$ & $1.3 \%$ & $0.0 \%$ & $1.3 \%$ & $0.0 \%$ & $0.0 \%$ & \begin{tabular}{|l|}
$0.0 \%$ \\
\end{tabular} & \begin{tabular}{|l|}
$0.0 \%$ \\
\end{tabular} & $0.0 \%$ & \begin{tabular}{l|l}
5 & $0.0 \%$ \\
\end{tabular} & $\begin{array}{ll}0.0 \% \\
\end{array}$ & $1.3 \%$ & $1.3 \%$ & $0.0 \%$ & $3.8 \%$ & \begin{tabular}{l|l} 
& $0.0 \%$ \\
\end{tabular} & $\begin{array}{ll}0 & 0.0 \% \\
\end{array}$ & $2.5 \%$ & \begin{tabular}{|l|l|}
$0.0 \%$ \\
\end{tabular} & $100.0 \%$ \\
\hline UK/LD & 22 & 1 & 0 & 1 & 0 & 0 & 0 & 1 & 1 & 15 & 4 & 8 & 0 & 0 & 0 & 0 & 0 & 0 & 3 & 2 & 115 \\
\hline$\%$ & $19.1 \%$ & \begin{tabular}{|l|l|}
$0.9 \%$ \\
\end{tabular} & \begin{tabular}{|l|l|}
$0.0 \%$ \\
\end{tabular} & $0.9 \%$ & $0.0 \%$ & $0.0 \%$ & $0.0 \%$ & $0.9 \%$ & \begin{tabular}{|l|}
$0.9 \%$ \\
\end{tabular} & $13.0 \%$ & \begin{tabular}{l|l} 
& $3.5 \%$ \\
\end{tabular} & $7.0 \%$ & $0.0 \%$ & $0.0 \%$ & $0.0 \%$ & $0.0 \%$ & $0.0 \%$ & $\begin{array}{ll} & 0.0 \% \\
\end{array}$ & $2.6 \%$ & $1.7 \%$ & $100.0 \%$ \\
\hline JP/TK & 2 & 2 & 0 & 0 & 0 & 0 & 1 & 0 & 0 & 10 & 0 & 0 & 0 & 0 & 1 & 0 & 0 & 0 & 2 & 0 & 34 \\
\hline$\%$ & $5.9 \%$ & $5.9 \%$ & \begin{tabular}{|l|l|}
$0.0 \%$ \\
\end{tabular} & $0.0 \%$ & $0.0 \%$ & $0.0 \%$ & $2.9 \%$ & $0.0 \%$ & \begin{tabular}{|l|}
$0.0 \%$ \\
\end{tabular} & $29.4 \%$ & \begin{tabular}{l|l}
$\%$ & $0.0 \%$ \\
\end{tabular} & $0.0 \%$ & $0.0 \%$ & $0.0 \%$ & $2.9 \%$ & $0.0 \%$ & $0.0 \%$ & $\begin{array}{ll} & 0.0 \% \\
\end{array}$ & $5.9 \%$ & \begin{tabular}{|l|l|}
$0.0 \%$ \\
\end{tabular} & $100.0 \%$ \\
\hline
\end{tabular}

*DTA contains one index and two subcategories $3 \mathrm{c}$ and $3 \mathrm{e}$ and will therefore differ from the output-income index

\subsubsection{Indicators of Machinami or scenery (1)}

GCP and DTA in the US tell a great deal about this category. This is shown that one of the main objectives of NYC BIDs is cleanliness and safety. Most of the data in NYC concerns sanitation and cleanliness (10 indicators representing 12.7\%), streetscape, beautification, and greenery (20 indicators representing $25.3 \%$ ) compared to LD (sanitation and cleanliness: 6 indicators representing 5.2\% with streetscape, beautification, and greenery: 9 indicators representing 7.8\%) and TK (sanitation and cleanliness with no indicators, and streetscape, beautification, and greenery having 2 indicators representing 5.9\%).

\subsubsection{Indicators of visitors (customers, passengers, travellers, tourists, etc.) (2)}

For the improvement and promotion of business in the district, indicators have provided much data, especially for LD where they emphasise marketing and events (12 indicators representing 10.4\%). This is shown that two of the main concerns of LD BIDs are business and economics. By contrast, most indicators for NYC concern transportation (11 indicators representing 13.9\%), and the data from Japan varies.

5.1.3 Indicators of real estate (rental costs, vacancy rates, etc.) (3)

NYC BIDs contain a lot of indicators in this category. It could be implied that BIDs in NYC places importance to such information. For LD, only the LCQ to 
PDC area has indicators in this category for two BIDs. In Tokyo, only OYM shows general information (3-a).

\subsubsection{Economic indicators (consumption activity, employment, etc.) (4)}

LD BIDs emphasise business (4 indicators representing 3.5\%) and activities (5 indicators representing $4.3 \%$ ). It is therefore certain that LD BIDs place emphasise on marketing. For the US, BIDs in NYC provide data on employment (3 indicators representing 3.8\%) followed by business ( 2 indicators representing $2.5 \%$ ) and investment (a single indicator representing 1.3\%). In Tokyo, there is only a single indicator $(2.9 \%)$ for employment and business.

\subsubsection{Indicators for disaster prevention, crime prevention or public safety (5)}

Each country places importance on this category, but there are different subcategories for each city. LD BIDs, especially VTR, provides the most indicators of public safety, crime prevention, and security (18 indicators) which overall means that LD BIDs provide the most information in these categories (22 indicators representing 19.1\%). On the one hand, TK emphasises relative disaster ( 2 indicators representing 5.9\%), though KBK emphasises more crime prevention and disaster compared to OYM in TK. Whereas, in NYC, DTA presents a great deal of information on public safety, crime prevention, and security (4 indicators representing 3.5\%), compared to GCP which only shows a single indicator $(1.3 \%)$ for public safety, crime prevention, and security (Table 3).

\subsubsection{Indicators for enhancing community power, mutual understanding, or networking (6)}

The number of indicators in this category is quite small, and there are two possible reasons for this. One is that it is difficult to show the performance or numerical information about community power, mutual understanding, and networking of all BIDs. The other is the small attention paid to enhancing them in all BIDs.

\subsubsection{Indicators for enhancing the popularity of the BID, ABM or their areas (7)}

For this category, LD BIDs in both VTR and the LCQ to PDC represent the most number of indicators compared to the other two cities. The survey data for newsletters and digital letter subscribers, and social media involved in the BID marketing programme (15 indicators representing $13 \%$ ), followed by others ( 8 indicators representing 7\%), public press, TV/newspapers (4 indicators representing 3.5). As previously mentioned, the purpose of each LD BID is to promote and enhance cities through marketing. For Japan, there is no such data available for OYM in this category, although many are represented in KBK, which shows that $\mathrm{ABM}$ in $\mathrm{TK}$ has a different way of disclosing indicators.

\subsubsection{Indicators of the competition between regions (increase in employees, population growth, etc.) (8)}

Only New York provides information for this category on population growth, and others (a single indicator representing 1.3\% for each). 


\subsubsection{Others (9)}

In this category, all cities represent indicators for ecology: New York (2 indicators representing $2.5 \%$ ), London (3 indicators representing $2.6 \%$ ) and Tokyo (2 indicators representing 5.9\%). This means that ecology is now an international issue for city management.

\subsection{Output-outcome}

In Table 5, indicators for New York present the highest output data compared to the others. New York represents information mostly on input and output, for example, sanitation and cleanliness (1-a), streetscape and beautification (1-c). However, London's indicators are more representative of output and outcome compared to others. The outcome information concerns marketing and communication (2-a), public safety and security (5-a), and newsletters and digital letter subscribers (7-c). The impact indicators are represented in every BID of three cities, normally obtained from the annual report. In addition, Japan presents a variety of information depending on the area.

Table 5: Indicators divided by output-outcome.

\begin{tabular}{|c|c|c|c|c|c|c|}
\hline BID & input & output & outcome & impact & $\begin{array}{c}\text { un- } \\
\text { identified }\end{array}$ & sum \\
\hline GCP & 3 & 14 & 3 & 7 & 3 & 30 \\
\hline$\%$ & 10 & 46.7 & 10 & 23.3 & 10 & 100 \\
\hline DTA & 6 & 19 & 0 & 21 & 2 & 48 \\
\hline$\%$ & 12.5 & 39.6 & 0 & 43.8 & 4.2 & 100 \\
\hline VTR & 5 & 28 & 32 & 3 & 4 & 72 \\
\hline$\%$ & 6.9 & 38.9 & 44.4 & 4.2 & 9 & 100 \\
\hline LSQtoPDC & 0 & 9 & 19 & 13 & 2 & 43 \\
\hline$\%$ & 0 & 20.9 & 44.2 & 30.2 & 4.7 & 100 \\
\hline OYM & 0 & 1 & 3 & 13 & 0 & 17 \\
\hline$\%$ & 0 & 5.9 & 17.6 & 76.5 & 0 & 100 \\
\hline KBK & 0 & 8 & 8 & 0 & 1 & 17 \\
\hline$\%$ & 0 & 47.1 & 47.1 & 0 & 5.9 & 100 \\
\hline sum & 14 & 79 & 65 & 57 & 12 & 227 \\
\hline$\%$ & 6.2 & 34.8 & 28.6 & 25.1101 & 5.3 & 100 \\
\hline
\end{tabular}

\subsection{Cross analysis}

Cross analysis shows how the indicators for nine categories represent outputoutcome. Indicators for sanitation and cleanliness (1-a) and streetscape, beautification, and greenery (1-b) are highly representative of output information. For indicators of visitors (2); they are highly representative of outcome information on marketing communications and special events (2-a). Impact is highly represented by transportation (2-b), visitor numbers (2-d), and (3) indicators for real 
estate, rental costs, or vacancy rates (3-a to 3-f). Public safety and security (5-a) and newsletters and digital letter subscribers (7-c) are represented in output and outcome.

Table 6: Cross analysis.

\begin{tabular}{|c|c|c|c|c|c|c|c|c|c|c|c|c|c|c|c|c|c|c|c|c|c|}
\hline & \multicolumn{3}{|c|}{ (1) } & \multicolumn{5}{|c|}{ (2) } & \multicolumn{7}{|c|}{ (3) } & \multicolumn{6}{|c|}{ (4) } \\
\hline & $1-a$ & $1-b$ & $1-c$ & $2-a$ & $2-b$ & $2-c$ & $2-d$ & $2-f$ & $3-a$ & $3-b$ & 3-c & $3-d$ & $3-e$ & 3-f & $3-g$ & 4-a & 4-b & 4-c & 4-d & 4-e & $4-f$ \\
\hline 1 imput & 5 & 1 & 0 & 0 & 0 & 1 & 0 & 0 & 0 & 0 & 0 & 0 & 0 & 0 & 0 & 1 & 0 & 2 & 0 & 0 & 0 \\
\hline 2 output & 11 & 29 & 3 & 2 & 2 & 4 & 0 & 0 & 0 & 0 & 0 & 0 & 0 & 0 & 0 & 0 & 0 & 0 & 1 & 0 & 0 \\
\hline 3 outocome & 0 & 0 & 1 & 12 & 3 & 2 & 1 & 0 & 0 & 0 & 0 & 0 & 0 & 0 & 0 & 0 & 4 & 0 & 4 & 0 & 0 \\
\hline 4 impact & 0 & 1 & 0 & 0 & 9 & 0 & 7 & 0 & 7 & 6 & 4 & 3 & 1 & 2 & 0 & 4 & 2 & 0 & 0 & 0 & 0 \\
\hline 5 unidentified & 0 & 0 & 0 & 1 & 1 & 0 & 0 & 0 & 0 & 0 & 0 & 0 & 0 & 0 & 0 & 0 & 1 & 0 & 0 & 0 & 0 \\
\hline \multirow[t]{3}{*}{ sum } & 16 & 31 & 4 & 15 & 15 & 7 & 8 & 0 & 7 & 6 & 4 & 3 & 1 & 2 & 0 & 5 & 7 & 2 & 5 & 0 & 0 \\
\hline & \multicolumn{3}{|c|}{ (5) } & \multicolumn{4}{|c|}{ (6) } & \multicolumn{5}{|c|}{ (7) } & & (3) & \multicolumn{6}{|c|}{ (9) } & \multirow{2}{*}{ total } \\
\hline & $5-a$ & $5-b$ & $5-c$ & $6-a$ & 6-b & 6-c & $6-d$ & $7-a$ & $7-b$ & $7-c$ & $7-d$ & $7-e$ & $8-a$ & 8-b & $9-a$ & $9-b$ & $9-c$ & $9-d$ & $9-e$ & $9-f$ & \\
\hline 1 imput & 4 & 0 & 0 & 0 & 0 & 0 & 0 & 0 & 0 & 0 & 0 & 0 & 0 & 0 & 0 & 0 & 0 & 0 & 0 & 0 & 14 \\
\hline 2 output & 11 & 1 & 1 & 0 & 1 & 0 & 0 & 0 & 0 & 6 & 0 & 4 & 0 & 0 & 1 & 0 & 0 & 0 & 0 & 2 & 79 \\
\hline 3 outocome & 8 & 1 & 0 & 1 & 0 & 0 & 1 & 0 & 0 & 18 & 3 & 4 & 0 & 0 & 0 & 0 & 0 & 0 & 2 & 0 & 65 \\
\hline 4 impact & 0 & 1 & 0 & 0 & 0 & 0 & 0 & 1 & 1 & 0 & 0 & 0 & 1 & 1 & 0 & 3 & 0 & 0 & 3 & 0 & 57 \\
\hline 5 unidentified & 5 & 0 & 0 & 0 & 0 & 0 & 0 & 0 & 0 & 1 & 1 & 0 & 0 & 0 & 0 & 0 & 0 & 0 & 2 & 0 & 12 \\
\hline sum & 28 & 3 & 1 & 1 & 1 & 0 & 1 & 1 & 1 & 25 & 4 & 8 & 1 & 1 & 1 & 3 & 0 & 0 & 7 & 2 & 227 \\
\hline
\end{tabular}

\section{Conclusion}

Tokyo ABMs disclose less data compared to the other two cities, and only two annual report has been disclosed among ABMs in Tokyo as mentioned previously (2.3). In addition, there are fewer indicators as shown in Tables 3 and 4. This is because Japan has no BIDs whereas BIDs in New York and London need to report their performance measurement for approximately five years by a voting process as the sunset provision. In conclusion, differences relate to the characteristics and purposes of the systems in each city. In the nine categories, New York emphasises indicators for cleanliness and greenery, streetscape, and beautification (5.1.1). For London, they emphasise marketing and economic (5.1.2, 5.1.4, and 5.1.7) according to their objective, and crime prevention (5.1.5). Whereas, in Tokyo there is less disclosure and areas vary (Tables 3 and 4) because of the lack of a BID system. For output-outcome (5.2), New York reports data by input and output. This shows that New York BIDs places importance to information on their activities and actions disclosed in the annual reports. London discloses many reports on output and outcome to present their performance following their objective which emphasis marketing to show the effect of activities. However, there are various styles for Tokyo ABMs, because there is no time limit or measurement by the sunset provision. Through the aforementioned research, indicators disclosed by BIDs in New York and London could be considered for introducing BIDs to Japan and other countries where no BIDs currently exist. The type of numerical information and performance indicators that should be applied to individual city characteristics or purposes for Japan or other countries may be considered by city management in the near future. It is hoped that the ideas on performance evaluation and information disclosure of BIDs in this paper may be used as key factors for sustainability in the next phase of urban development and city management. 


\section{Acknowledgement}

The studies presented here were carried out with funds provided by NIKKEN SEKKEI Research Institute. The authors are grateful for this financial support.

\section{References}

[1] Sandford, M. Business Improvement Districts. Online. http://research briefings.files.parliament.uk

[2] Kyoto, U., MLIT and Wakayama, U. Simple aggregate results of questionnaire about implementation and effect of Area Based Management (in Japanese). Online. www.gsm.kyoto-u.ac.jp

[3] Small Business Services (SBS), NYC. Fiscal year 2015 Business Improvement Districts Trends Report. Online. www.nyc.gov

[4] Department for Communities and Local Government. The Development and Implementation of Business Improvement Districts. London, 2007.

[5] Puks, M. Key performance Indicators (KPIs) for Business Improvement Districts (BIDs): Practice manual for BIDs developing, implementating and using meaningful KPIs. British BID Academy, UK, 2014.

[6] Findley, A. and Sparks, L. The retail planning knowledge base briefing paper; Business Improvement District (BIDs). Institute for Retail Studies. Scotland: University of Stirling, Scotland, 2008.

[7] Grand Central Partnership. Annual report 2014. Highlighting an Historic Year. Online. www.grandcentralpartnership.nyc

[8] Alliance for downtown New York. Financial statements and auditors report June 30, 2013 and 2014. Online. www.downtownny.com

[9] Victoria Business Improvement District. 2014/2015 Annual report. Victoria London starts here. Online. www.victoriabid.co.uk

[10] Heart of London. Heart of London: The Power of Partnership Annual Report 2012/2013. Online. www.heartoflondonbid.london

[11] The Council for Area Development and Management. Area Management Report 2016 Otemachi Marunouchi Yurakucho (in Japanese). Online. www.otemachi-marunouchi-yurakucho.jp

[12] Kabukicho Town Management. Annual report year 2015 (in Japanese). Online. https://www.d-kabukicho.co

[13] Hirayama, I. and Mitarai, J. An Analysis of the Mechanism that Area based Management Affects the Land Prices. Journal of the City Planning Institute of Japan 51-3, pp. 474-480, The City Planning Institute of Japan, 2016 (in Japanese). 